DOI: 10.12731/2070-7568-2020-4-31-60

УДК 330.59

\title{
МОНЕТАРНОЕ НЕРАВЕНСТВО И ИНФЛЯЦИЯ: ОФИЦИАЛЬНАЯ СТАТИСТИКА И ОЦЕНКИ РОССИЯН
}

\author{
Россошанский А.И., Белехова Г.В.
}

Затяжной характер существенной доходной дифференциащия населения и нестабильность потребительских ичен влияют на неравномерное распределение ресурсов и жизненных возможностей среди различных групп населения, подвергая некоторые из них повышенному риску экономической уязвимости. Данные проблемы ещуе более усугубляются в периоды нестабильности социально-экономической жизни, вызванной политическими, техногенными или природныли (например, пандемия 2020 г.) причинами. В связи с этим научную и практическую значимость приобретают задачи анализа складывающейся динамики неравенства и инфлячии и выявления на этой основе рисков для благополучия населения.

Цель работы: изучение тендениий монетарного неравенства и инфлячии, складывающихся на фоне протекания пандемии, и выявление возможных рисков для материального благополучия россиян.

Метод или методология проведения работы: общенаучные методы (анализ и синтез), динамический анализ официильных статистических данных и результатов национальных социологических опросов населения.

Результаты: проанализированы динамика показателей доходного неравенства и инфлячии, структура потребительских расходов, объемы вкладных и кредитных операций населения, тенденции восприятия населением материального положения и инфляции, практики адаптации населения в условиях карантинных ограничений. Выявлены современные тенденции социально-экономического положения и возможные риски для населения.

Область применения результатов: результаты исследования могут быть использованы федеральными органами государствен- 
ной власти для разработки направлений сочиальной политики по борьбе с бедностью и сокращуению неравенства, для разработки направлений денежно-кредитной политики по снижению инфляцчии, а также научными работниками, интересующимися данной тематикой.

Ключевые слова: доходное неравенство; инфляция; настроения населения; потребительские расходы; экономия; адаптащия.

\section{MONETARY INEQUALITY \\ AND INFLATION IN RUSSIA: OFFICIAL STATISTICS AND ASSESSMENTS OF POPULATION}

\section{Rossoshanskii A.A., Belekhova G.V.}

The longstanding nature of significant income differentiation of the population and the instability of consumer prices affect the uneven distribution of resources and life opportunities among different groups of the population, exposing some of them to an increased risk of economic vulnerability. These problems are even more made worse during periods of instability in socio-economic life caused by political, anthropogenic or natural (for example, pandemic 2020) reasons. In this regard, the tasks of analyzing the emerging dynamics of inequality and inflation and identifying, on this basis, risks to the well-being of the population, acquire scientific and practical significance.

Purpose: The goal of our work is to study the trends of income inequality and inflation, developing against the background of the pandemic, and to identify possible risks to the material wellbeing of Russians.

Method or methodology: The paper uses general scientific methods (analysis and synthesis), dynamic analysis of official statistical data and materials of national sociological surveys.

Results: We analyzed the dynamics of main indicators of income inequality and inflation, the structure of consumer spending, the volume of deposit and credit transactions of the population, trends in the population's perception of the financial situation and inflation, the practice 
of adaptation of the population in conditions of quarantine restrictions. We revealed the current trends in the socio-economic situation and possible risks for the population.

Practical implications: The results of the study can be used by federal public authorities to develop social policy directions for lifting people out of poverty and reduce inequality, to develop monetary policy directions to reduce inflation, as well as by researchers interested in this topic.

Keywords: income inequality; inflation; population sentiment; consumer spending; economy effort; adaptation.

\section{Введение}

Основополагающие идеи экономической теории, также как и принципы построения социального государства, предполагают стремление к цели в виде роста общественного благосостояния, а не его распределения между различными группами населения. «Положение людей остается фундаментально неравным во всех странах, включая и самые развитые постиндустриальные государства, и, несмотря на активную социальную политику, до сих пор встречаются свидетельства бедности и массового экономического и социального неравенства» [32, с. 7].

В Конституции РФ (ст. 7) провозглашено, что Россия - социальное государство, соответственно первостепенной задачей власти выступает создание условий для развития общества на основе принципов социальной справедливости и взаимной ответственности в целях обеспечения достойной и благополучной жизни для каждого гражданина. Особенностью социальной политики в России является ориентация на адресную помощь беднейшим слоям населения, которая по своей сути не способна решить проблему глубокого социального неравенства, а лишь сглаживает некоторые негативные последствия для определенных групп населения.

За годы восстановительного роста экономики в 2000-2008 гг. изменилось представление россиян о нормальных потребностях и возможностях. Однако «социальная сфера не успела адаптироваться к этому. Население, и в первую очередь «средний класс», обра- 
зованные и хорошо зарабатывающие люди, в своей массе остается неудовлетворенным уровнем социальных услуг» [26]. В частности, проблема «разделения общества на богатых и бедных» всегда стоит в перечне одних из наиболее актуальных общественных проблем (табл. 1). Наряду с ней, постоянное беспокойство у населения вызывают темпы роста цен на товары и услуги первой необходимости (табл. 1), что вполне закономерно, ведь ценовая стабильность является неотъемлемым элементом благополучной жизни людей и устойчивого экономического роста. «При прочих равных условиях высокая инфляция способствует усилению социального неравенства, росту дифференциации доходов, так как наиболее негативно влияет на благополучие людей с низким уровнем достатка» [24].

Таблица 1.

Распределение ответов на вопрос: «Какие проблемы беспокоят Вас в первую очередь?» (\% от общего количества опрошенных)

\begin{tabular}{|c|c|c|c|c|c|c|c|c|c|c|}
\hline \multirow{2}{*}{ Проблема* } & \multicolumn{2}{|c|}{2001 год } & \multicolumn{2}{|c|}{2005 год } & \multicolumn{2}{|c|}{2010 год } & \multicolumn{2}{|c|}{2015 год } & \multicolumn{2}{|c|}{2017 год } \\
\hline & $\%$ & ранг & $\%$ & ранг & $\%$ & ранг & $\%$ & ранг & $\%$ & ранг \\
\hline Дороговизна жизни & 66 & 1 & 60 & 1 & 51 & 1 & 55 & 1 & 65 & 1 \\
\hline Произвол чиновников & 32 & 6 & 29 & 5 & 31 & 5 & 33 & 2 & 41 & 2 \\
\hline $\begin{array}{l}\text { Повышение тарифов } \\
\text { на услуги ЖКХ** }\end{array}$ & н.д. & н.д. & 46 & 2 & 38 & 2 & 30 & 4 & 34 & 3 \\
\hline $\begin{array}{l}\text { Повышение цен на продукты } \\
\text { питания** }\end{array}$ & н.д. & н.д. & н.д. & н.д. & 29 & 6 & 32 & 3 & 33 & 4 \\
\hline $\begin{array}{l}\text { Разделение общества } \\
\text { на богатых и бедных }\end{array}$ & 33 & 4 & 23 & 10 & 20 & 13 & 22 & 7 & 29 & 5 \\
\hline Безработица & 31 & 8 & 22 & 11 & 26 & 7 & 27 & 5 & 27 & 6 \\
\hline Терроризм & 27 & 10 & 26 & 8 & 24 & 10 & 8 & 20 & 25 & 7 \\
\hline Преступность & 51 & 2 & 32 & 4 & 33 & 3 & 17 & 10 & 22 & 8 \\
\hline Падение нравов, культуры & 32 & 6 & 26 & 8 & 26 & 7 & 21 & 8 & 21 & 9 \\
\hline Страх перед будущим** & н.д. & н.д. & н.д. & н.д. & н.д. & н.д. & 14 & 13 & 20 & 10 \\
\hline
\end{tabular}

Источник: [9].

Высокая практическая необходимость сглаживания чрезмерной социальной дифференциации и претворения в жизнь конституцион- 
ного положения о социальном государстве обусловливает повышенное внимание к проблемам доходного (монетарного) неравенства и инфляции. О важности результативной работы в этих направлениях отмечено в январском (2020 г.) Послании Президента РФ Федеральному Собранию РФ и в Указе Президента РФ от 21 июля 2020 г. № 474 «О национальных целях развития Российской Федерации на период до 2030 года». Новые геополитические и эпидемиологические вызовы существенно усложняют ситуацию с неравенством и устойчивостью цен, проявляясь в нестабильности систем социальной защиты, бедственном положении уязвимых групп населения (пожилые, инвалиды, многодетные семьи и т.д.). В данном контексте особый научный и практический интерес представляет выявление современных тенденций монетарного неравенства и инфляции и определение возможных рисков для благополучия населения России, что и составило иель проведенного исследования. Задачами исследования явились изучение динамики основных показателей доходного неравенства и уровня бедности; анализ потребительских расходов, вкладных и кредитных операций населения; рассмотрение динамики официальной и воспринимаемой населением инфляции; анализ поведенческих практик россиян в контексте адаптации к изменившимся в период пандемии социально-экономическим условиям.

\section{Обзор литературы}

Тематика монетарного неравенства и ценовой стабильности находит широкое отражение в трудах отечественных и зарубежных исследователей. Чаще всего рассматриваются концептуальные вопросы о сущности неравенства, методические аспекты оценки масштабов неравенства и определения величины инфляции для разных групп населения, а также эффективность мер социально-экономической политики по сокращению неравенства и бедности [1, 5, 20, 37].

Исследования проводятся преимущественно в рамках комплексного экономико-социологического подхода. В частности, следует отметить представительные работы Анисимовой Г.В. и Мареевой С.В. о масштабах монетарного неравенства в России вплоть до 2019 г., включая международные сопоставления, обращение к вопросу о 
стратификации российского общества и проблеме концентрации доходов и богатства $[3,19]$. Примером комплексного подхода являются и публикации коллектива авторов под руководством В.Н. Бобкова, в которых анализируется социально-экономическое неравенство населения и связанные с ним проблемы межрегионального неравенства в качестве и уровне жизни населения [6], вопросы социальной стратификации и определения критериев для идентификации групп населения с различающимся уровнем и качеством жизни [7].

Наряду с этим, показатели доходного неравенства используются в смежных исследованиях, в частности, при изучении уровня жизни отдельных социальных групп (например, семей с детьми [14]), или в качестве индикаторов в оценке эффективности деятельности органов государственной власти [10].

Отдельный пласт составляют работы, в которых проблематика неравенства рассматривается на фоне изменений в социально-экономической жизни общества. Например, исследование [36] про динамику неравенства в Центральной и Восточной Европе во время рецессии 2008-2012 гг., в котором авторы доказали значимое влияние сокращения полной занятости на снижение доходов и усиление дифференциации населения по доходам. В последнее время появляются публикации об изменении социально-экономического положения населения в период пандемии коронавируса. На примере Китая изучено изменение уровня дохода работников и выделены факторы экономической устойчивости, среди которых образование, накопленное богатство, занятость в государственном секторе и на городских предприятиях [39]. Неравномерное воздействие последствий пандемии на неравенство населения и другие аспекты социально-экономической жизни отражено в исследованиях по Великобритании [34] и странам Латинской Америки и Карибского бассейна [35]. В них подчеркивается, что вероятность ухудшения материального положения наиболее высока для молодых работников, самозанятых, а также лиц, работа которых в удаленном формате затруднена или невозможна.

Что касается феномена инфляции, то в последние годы стали появляться исследования, развивающие гипотезу о том, что сниже- 
ние инфляции в результате жесткой денежно-кредитной политики негативно сказывается на экономическом развитии страны и приводит к уменьшению реальных доходов россиян $[13,15]$. В одном из свежих исследований отечественным ученым удалось получить свидетельства того, что снижение инфляции до целевого ориентира Банка России не способствовало смягчению неравенства, а, наоборот, усугубило его. Однако количественный эффект воздействия инфляции оказался не сильным - снижение инфляции с 10 до 4 п.п. привело к росту коэффициента Джини только на 0,006 [17, с. 63].

Таким образом, заметен высокий интерес научной общественности к проблематике монетарного неравенства и инфляции. Принимая во внимание современную ситуацию, во многом определяемую мероприятиями по борьбе с пандемией, важно отслеживать и анализировать текущую динамику ключевых показателей дифференциации населения и динамику цен, что позволит своевременно оценить риски для материального благополучия населения и разработать соответствующие корректирующие воздействия.

\section{Материалы и методы исследования}

Информационную базу исследования составили данные Федеральной государственной службы статистики и Центрального Банка Российской Федерации, а также результаты одной из волн общенационального опроса Фонда «Общественное мнение» (ФОМ) «КоронаФОМ. Экономика и Пандемия (ЭиП)». В рамках всероссийского репрезентативного опроса ФОМ, проведенного 29 сентября - 9 октября 2020 г. в 105 населенных пунктах из 55 субъектов РФ [25], было опрошено население в возрасте от 18 лет и старше. Общий объем выборки составил 2007 респондентов. Метод исследования: интервью по месту жительства в режиме «face-to-face». Статистическая погрешность не превышает 3,3\%.

Для выявления тенденций социально-экономического положения и возможных рисков использованы общенаучные методы (анализ и синтез) и динамический анализ статистических и социологических данных. 


\section{Результаты и их обсуждение}

Неравенство. Несмотря на общий прогресс российского общества в плане сокращения неравенства и бедности, эти задачи по-прежнему актуальны. Коэффициент фондов, показывающий масштабы расслоения населения по уровню доходов, с 2003 г. не отпускался ниже 15 раз (рис. 1), тогда как по современным меркам нормальным считается неравенство, при котором отношение доходов 10\% наиболее богатых к доходам 10\% наиболее бедных не превышает 6-8 раз [18, с. 11-12]. Значение индекса Джини, отражающего степень неравномерности распределения населения по денежным доходам, также с 2003 г. стабильно превышает отметку в 0,400 (рис. 1). Такой уровень индекса Джини (выше 0,4), согласно позиции Всемирного банка, свидетельствует о наличии в стране избыточного неравенства, которое, в свою очередь, негативно влияет на темпы экономического роста [38]. Следовательно, и по международным стандартам, и по мнению ведущих отечественных исследователей $[11,31]$, российское общество на протяжении уже более чем двадцатилетнего периода находится далеко за пределами допустимых границ социально-экономического неравенства. Важно понимать, что стабилизация показателей неравенства, фиксируемая официальной статистикой в последние годы, обеспечивается за счёт снижения доходов наиболее обеспеченных групп населения при одновременном обогащении «элитных и субэлитных слоёв» [29]. При этом материальное положение наименее обеспеченных групп населения значительно не улучшается.

Уровень бедности, т.е. доля людей с доходами ниже прожиточного минимума в общей численности населения, стал активно сокращаться в начале «нулевых», в период восстановительного роста экономики, однако с 2008 г. ситуация относительно стабильна значение показателя колеблется в пределах 11-13\% (рис. 1). По состоянию на 1-ое полугодие 2020 г. численность бедного населения составляет 19,4 млн. человек или $13,2 \%$ от общей численности населения. При этом порядка $10 \%$ россиян находятся на границе бедности [2]. 


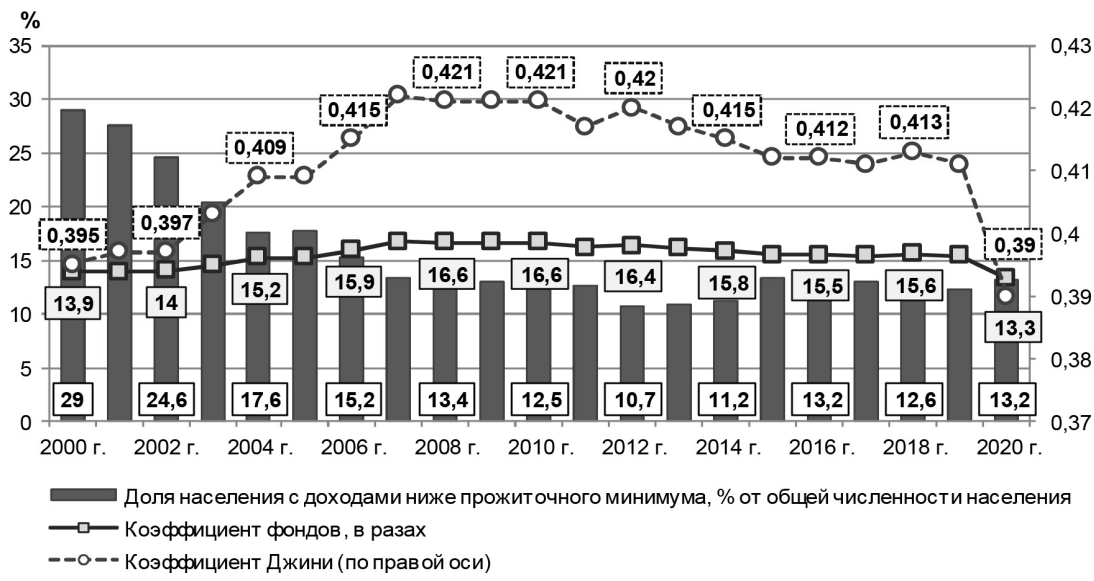

Рис. 1. Динамика реальных денежных доходов населения и коэффициента фондов в России, 1995-2016 гг.

Примечание: данные за 2020 г. соответствуют I-ому полугодию 2020 г. Источник: данные Росстата.

Эксперты отмечают [30], что следует более аккуратно подходить к интерпретации процессов снижения и стабилизации уровня бедности, поскольку методика определения прожиточного минимума (ПМ) в России направлена на его заведомое занижение. Прожиточный минимум используется при расчете государственных гарантий (МРОТ, стипендий, пособий и др.), для оценки уровня жизни населения, при формировании федерального и региональных бюджетов и т.д., и при общей установке на экономию на социальных расходах это не могло не сказаться на подходах к его расчету - последний пересмотр минимальных норм потребления был в 2013 г., когда доля расходов на приобретение продуктов питания была установлена на уровне от 40 до $60 \%$ в зависимости от климатической зоны ${ }^{1}$. Другими словами, ПМ в России устанавливается таким образом, чтобы доля официально нуждающихся в социальной поддержке граждан была минимальной. Немаловажно и то, что в России используется абсолютный подход к оценке уровня бедности, тогда как во многих

${ }^{1}$ Актуализированная потребительская корзина, используемая для расчета прожиточного минимума, должна вступить в действие в 2021 году. 
государствах ориентируются на относительную концепцию бедности, согласно которой расчет ведется от медианного дохода, что обеспечивает более высокие стандарты жизнедеятельности населения.

Что же касается среднедушевых денежных доходов населения России, то вплоть до 2014 г. для них был характерен волнообразный рост. Далее начался затяжной спад доходов, продлившийся вплоть до 2019 г., когда был отмечен незначительный прирост реальных располагаемых денежных доходов $(+0,8 \%)$, чему способствовало, прежде всего, снижение уровня потребительской инфляции $(3,0 \%$ в 2019 г. после 4,3\% в 2018 г.) [8, с. 4]. В первом квартале 2020 г. также наблюдалась слабо положительная динамика доходов - прирост составил $+0,7 \%$ по сравнению с аналогичным периодом предыдущего года. Но уже во втором квартале 2020 г. реальные располагаемые денежные доходы населения сократились на 8\% (по сравнению со вторым кварталом 2019 г.). «Основной причиной падения стали ограничительные меры, введенные в целях борьбы с распространением эпидемии. По оценкам Росстата в первом полугодии 2020 г. реальные располагаемые денежные доходы населения составили 96,3\% от уровня первого полугодия 2019 г.» [21, с. 5].

Низкая материальная обеспеченность большей части населения оказывает закономерное влияние на структуру потребления. С одной стороны, за почти двадцатилетний период структура потребительских расходов российских домохозяйств претерпела положительные изменения в части сокращения доли расходов на покупку продуктов питания почти на 10\% (рис.2). С другой стороны, в большинстве развитых странах (Австрия, Великобритания, Франция, Чехия, Швейцария) удельный вес расходов на питание в среднем не превышает $10-15 \%$ [23, 33]. Кроме того, если рассмотреть структуру потребительских расходов в разрезе доходных групп населения, то станет ясна острота дифференциации (рис. 3). У наименее обеспеченных слоев населения расходы на питание существенно превалируют над другими статьями расходов (более 50\% в 2019 г. - первой половине 2020 г.), тогда как у наиболее обеспеченной группы на питание направляется около трети потребительских расходов. Наряду с этим, 
наиболее обеспеченная группа населения расходует заметно большую долю средств на приобретение непродовольственных товаров (35\% против 23\% в наименее обеспеченной группе населения).

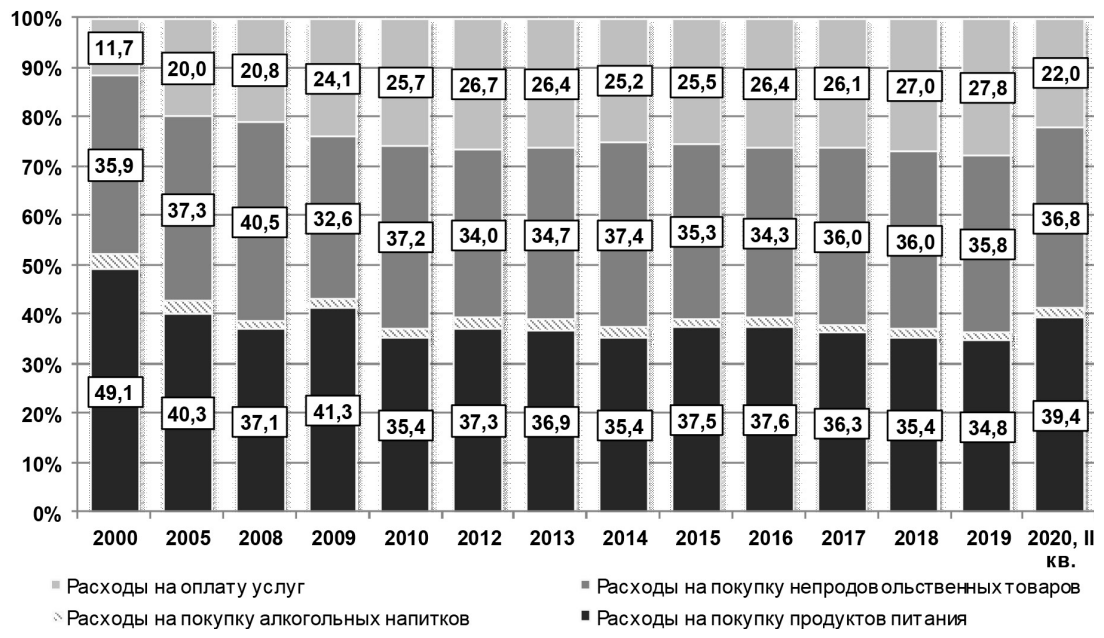

Рис. 2. Структура потребительских расходов домашних хозяйств России, \% Источник: данные Росстата.

Актуальные данные социологических опросов позволяют оценить остроту последствий карантинных ограничений 2020 года. В частности, почти у половины работающих россиян (49\%) существенно сократились доходы с начала ограничительных мероприятий в России, столько же россиян (46\%) боятся, что их семье не на что будет жить и не будет хватать денег даже на еду ${ }^{1}$. При этом большая часть населения России (порядка 64\%) не имеет накоплений. Из тех, кто имеет накопления, 21\% сможет жить на них не более 1 месяца, $45 \%$ - от 2 до 6 месяцев, еще 16\% - от полугода до года²

${ }^{1}$ Опрос компании Online Market Intelligence (OMI) и Центра социального проектирования «Платформа». Объем выборки 1000 респондентов. Период сбора данных 9-10 апреля 2020 г.

${ }^{2}$ Исследование проведено научно-техническим центром «Перспектива» по заказу страховой компании «Росгосстрах Жизнь» и банка «Открытие». Объем выборки 1500 респондентов. Период сбора данных 26 февраля - 3 марта 2020 г. Большинство опрошенных проживают в Центральном $(22,3 \%)$ и Приволжском ФО 


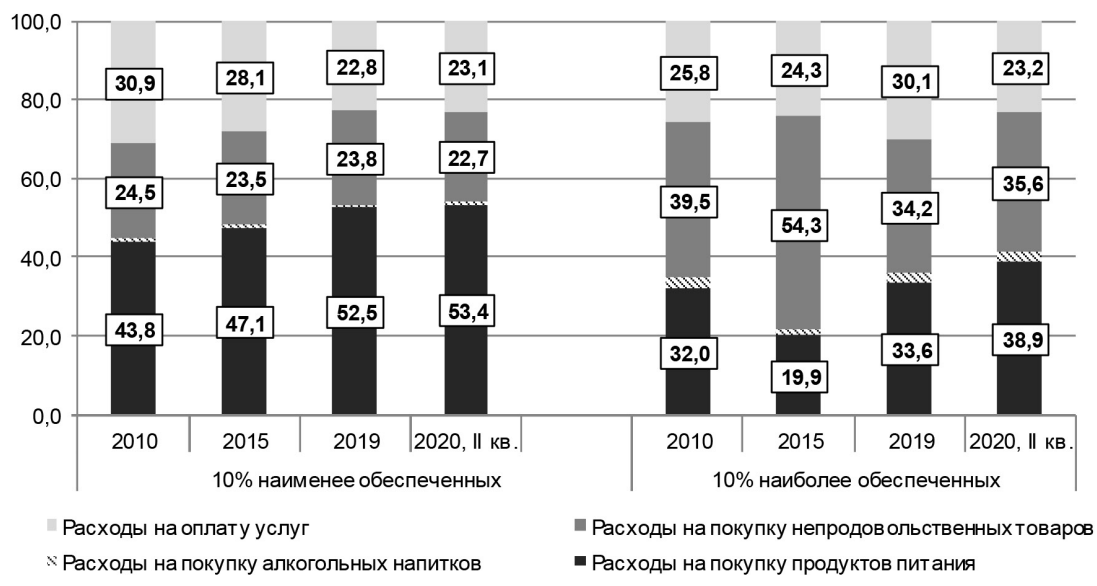

Рис. 3. Структура потребительских расходов наименее и наиболее обеспеченных домашних хозяйств, \%

Источник: данные Росстата.

По информации РБК и проекта SberIndex, «по итогам ноября в целом потребительские расходы россиян сократились год к году на 9,9\%. Сильнее расходы падали только в апреле (на 26,2\%) и мае (на $16,8 \%$ ), когда в стране были введены жесткие карантинные меры, призванные ограничить распространение коронавирусной инфекции. Остановить падение потребительского спроса в ноябре не помогли даже приуроченные к «черной пятнице» распродажи» [27].

Состояние вкладных и кредитных операций населения критически не изменяется. Согласно данным Центрального банка Российской Федерации, колебания банковских вкладов и кредитования находятся в рамках обыкновенной динамики (рис. 4). Ежемесячные темпы прироста вкладов физических лиц за март $(+2,1 \%)$ и апрель $(+2,1 \%)$ 2020 г. несколько превышали уровни 2019 г. (+1,5\% и +0,2\%). Показатели за август $(+1,3 \%)$ и сентябрь $(+0,3 \%)$ сопоставимы с данными

(20,2\%). Наименьшее количество опрошенных составили жители Москвы $(4,3 \%)$ и Санкт-Петербурга $(2,7 \%)$. Большая часть респондентов $(56,8 \%)$ имеет доход до 25 тыс. руб. На доход в диапазоне от 25 тыс. до 50 тыс. руб. живут $26,8 \%$ участников, 7,6\% располагают доходом от 50 тыс. до 100 тыс. руб. Наименьшую долю составили опрошенные с доходом более 100 тыс. руб. $-1,8 \%$. 
за 2019 г. (+0,2\% и +1,4\%). При этом показатели годового прироста вкладов в 2020 г. оказались выше показателей 2019 года. Ежемесячные темпы прироста кредитования физических лиц за март и апрель 2020 г. аналогичны уровню 2019 г. ( $+1,2 \%$ и $+1,7 \%$ соответственно); также весьма схожи ежемесячные приросты в августе-сентябре 2019 и 2020 гг. (рисунок). При этом показатели годового прироста кредитования физических лиц в 2020 г. оказались ниже уровня 2019 года.

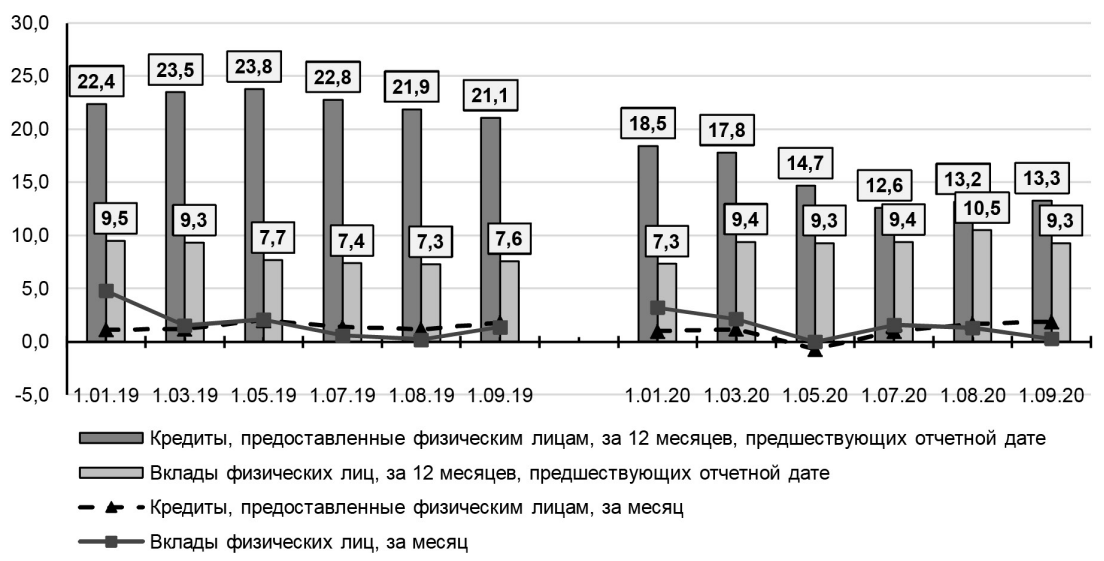

Pис. 4. Темпы прироста показателей банковского сектора Российской федерации (\% за период)

Источник: составлено авторами по: [22].

В абсолютном выражении объемы вкладов и кредитования выросли: в сентябре 2020 г. объем вкладов физических лиц составил 32215 млрд. руб., что почти на 9\% выше значений сентября 2019 г. (29589 млрд. руб. в сопоставимом выражении); объем кредитования физических лиц составил 18998 млрд. руб., что на 12,6\% выше значений сентября 2019 г. (16869 млрд. руб. в сопоставимом выражении); объем просроченной задолженности по кредитам составил 910 млрд. руб., что на 11,5\% выше значений сентября 2019 г. (816 млрд. руб. в сопоставимом выражении). Таким образом, несмотря на ограничения экономической деятельности и снижение доходов многих групп населения из-за сложной эпидемиологической обстановки, финансовая активность населения критически не изменилась. 
Отсутствие заметных позитивных сдвигов в жизни россиян, особенно начиная с 2017 г., подтверждается самооценками финансового положения (табл. 2). В 2020 г., как в 2008 г. и в 2014 г., самой массовой группой (почти 50\%) российского общества являются «малообеспеченные», которые не могут позволить себе покупку товаров длительного пользования. Второй по численности является группа «среднеобеспеченного» населения, наполняемость которой в 2020 г. находится на уровне 2014 года. Здесь важно отметить, что в денежном выражении доход данных групп выглядит весьма скромным: согласно исследованию ФНИСЦ РАН (июнь 2019 г.), «среднеобеспеченными» себя считают люди с месячным доходом до 22800 руб. на человека, бедными - до 15200 рублей» [28].

Таблицуа 2.

Самооценка финансового положения населением РФ в 2008-2017 гг. (\% от общего числа опрошенных)

\begin{tabular}{|l|c|c|c|c|c|c|c|c|c|c|}
\hline \multirow{2}{*}{ Характеристика } & \multicolumn{9}{|c|}{ Год } \\
\cline { 2 - 11 } & $\mathbf{2 0 0 8}$ & $\mathbf{2 0 0 9}$ & $\mathbf{2 0 1 0}$ & $\mathbf{2 0 1 4}$ & $\mathbf{2 0 1 5}$ & $\mathbf{2 0 1 6}$ & $\mathbf{2 0 1 7}$ & $\mathbf{2 0 1 8}$ & $\mathbf{2 0 1 9}$ & $\begin{array}{c}\mathbf{2 0 2 0} \\
\text { II } \\
\text { кв. }\end{array}$ \\
\hline $\begin{array}{l}\text { Не хватает денег даже на еду } \\
\text { («бедные») }\end{array}$ & 1,9 & 1,6 & 1,8 & 1,1 & 1,2 & 1 & 0,9 & 0,9 & 0,5 & 0,3 \\
\hline $\begin{array}{l}\text { Денег хватает на еду, но за- } \\
\text { труднительно покупать одежду } \\
\text { и оплачивать жилищно-комму- } \\
\text { нальные услуги («бедные) }\end{array}$ & 22,8 & 23,7 & 24,1 & 18,8 & 19,4 & 20,5 & 19,2 & 15,7 & 13,4 & 13,6 \\
\hline $\begin{array}{l}\text { Денег хватает на еду и одежду, } \\
\text { но не могут позволить покупку } \\
\text { товаров длительного пользова- } \\
\text { ния («малообеспеченные») }\end{array}$ & 45,7 & 45 & 43,7 & 45 & 45,3 & 47,6 & 49,5 & 50,3 & 50,3 & 49,9 \\
\hline $\begin{array}{l}\text { Денег хватает на еду, одежду } \\
\text { и товары длительного поль- } \\
\text { зования, но не хватает на по- } \\
\text { купку автомобиля, квартиры } \\
\text { (щсреднеобеспеченные») }\end{array}$ & 26,5 & 26 & 27,2 & 32 & 29,7 & 26,7 & 26,6 & 29,5 & 31,8 & 33,4 \\
\hline $\begin{array}{l}\text { Средств достаточно, чтобы } \\
\text { купить все, что считают нуж- } \\
\text { ным («высокообеспеченные) }\end{array}$ & 1,9 & 2,5 & 2,3 & 2,6 & 2,4 & 3 & 2,9 & 3,1 & 3,5 & 2,8 \\
\hline Затруднились ответить & 1,2 & 1,2 & 0,9 & 0,5 & 2 & 1,2 & 0,9 & 0,5 & 0,5 & 0,0 \\
\hline
\end{tabular}

Источник. Доходы, расходы и потребление домашних хозяйств / Росстат. URL: https://rosstat.gov.ru/compendium/document/13271\# 
Согласно данным октябрьского опроса ФОМ, материальное положение населения, несмотря на нестабильность ситуации в первой половине 2020 г., аналогично ситуации 2019 года. Большая часть опрошенных не имеет сбережений (63\% в октябре 2019 г., $64 \%$ в октябре 2020 г.) и кредитов (55\% и 57\% соответственно), предпочитает откладывать деньги, а не покупать дорогостоящие товары (54\% и 59\% соответственно), а также экономила и отказывалась от запланированных покупок за последний год (по 75\% в 2019 г. и 2020 г.).

Различия выявляются при сопоставлении групп, полярных по самооценке материального положения - «бедных» («денег не хватает даже на питание»; у 68\% из них доход на одного члена семьи не превышает 11 тыс. руб.) и «обеспеченных» («денег хватает на всё, кроме таких дорогих приобретений, как квартира, дом» и «материальных затруднений не испытываем, при необходимости могли бы приобрести квартиру, дом»; у 22\% из этой группы доход на одного члена семьи составляет от 13751 до 22500 руб., у 30\% - доход более 22500 руб.).

За последний год практически половина (47\%) обеспеченных ни на чем не экономила и не отказывалась от запланированных покупок, тогда как среди бедных таких только 8\% (табл. 3). Чаще всего бедные экономили на одежде и обуви (60\% против $10 \%$ среди обеспеченных), продуктах питания (53\% против 5\%), ремонте (40\% против 11\%), медицинских услугах (37\% против 6\%). Соответственно, изменилось потребительское и финансовое поведение данных групп населения. Представители бедных слоев населения чаще отмечали, что им пришлось сокращать покупки товаров и услуг (41\% по сравнению с 9\% среди обеспеченных), покупать более дешевую продукцию (42\% и $11 \%$ соответственно) или совершать покупки по акциям и распродажам (34\% и $18 \%$ соответственно). Обеспеченному населению не пришлось столь серьезно изменять свои потребительские привычки, при этом четверть из них $(25 \%)$ с началом пандемии стали сберегать деньги «на всякий случай» (табл. 3). 
Таблицуа 3.

Варианты экономии и изменение потребительского поведения населения (\% от общего числа опрошенных)

\begin{tabular}{|c|c|c|}
\hline \multirow[t]{2}{*}{ Вариант ответа } & \multicolumn{2}{|c|}{$\begin{array}{c}\text { Самооценка } \\
\text { материального } \\
\text { положения семьи }\end{array}$} \\
\hline & бедные & обеспеченные \\
\hline \multicolumn{3}{|c|}{$\begin{array}{c}\text { От чего именно приходилось отказываться } \\
\text { или на чём экономить за последний год?* }\end{array}$} \\
\hline одежда, обувь, кожгалантерея & 60 & 10 \\
\hline те или иные продукты питания & 53 & 5 \\
\hline ремонт & 40 & 11 \\
\hline медицинские услуги, лекарства & 37 & 6 \\
\hline $\begin{array}{l}\text { товары повседневного спроса (бытовая химия, } \\
\text { парфюмерно-косметические товары и т.д.) }\end{array}$ & 34 & 5 \\
\hline бытовая техника, электроника, мебель & 34 & 9 \\
\hline отдых, поездки по России или за границу & 34 & 21 \\
\hline проведение досуга (кафе, рестораны, кино, театры и т.п.) & 27 & 13 \\
\hline табак, сигареты, алкоголь & 16 & 5 \\
\hline ни на чём не экономим & 8 & 47 \\
\hline \multicolumn{3}{|c|}{$\begin{array}{c}\text { Что из перечисленного Вы начали делать именно из-за эпидемии коронавируса } \\
\text { и её последствий и продолжаете делать до сих пор? * }\end{array}$} \\
\hline откладывать деньги, сберегать «на всякий случай» & 8 & 25 \\
\hline $\begin{array}{l}\text { покупать продукты и товары по акциям, скидкам, } \\
\text { на распродажах }\end{array}$ & 34 & 18 \\
\hline покупать более дешёвые, чем раньше, продукты и товары & 42 & 11 \\
\hline $\begin{array}{l}\text { сокращать покупки каких-либо товаров и продуктов, } \\
\text { отказываться от покупок }\end{array}$ & 41 & 9 \\
\hline брать деньги в долг у родственников и знакомых & 14 & 1 \\
\hline ничего не начал(-а) делать & 27 & 41 \\
\hline \multicolumn{3}{|c|}{$\begin{array}{l}\text { * Примечание: сумма ответов не равна } 100 \% \text {, т.к. возможно несколько вариантов } \\
\text { ответа. }\end{array}$} \\
\hline
\end{tabular}

Источник: составлено авторами по: [25].

Можно предположить, что за предыдущие периоды экономической нестабильности, последний из которых пришелся на 20152017 гг, россияне в основной своей массе пересмотрели потребительское и финансовое поведение, стали более критичными и чувствительными к ценам, стали чаще применять «практики сравнения цен, покупок товаров по акциям и специальным предложе- 
ниям, покупок товаров более доступных брендов, а также практики планирования покупок» [12], т.е. научились оперативно адаптироваться к материальным ограничениям.

Инфляция. Политика Центрального банка Российской Федерации с начала 2014 г., состоящая в переходе к режиму таргетирования инфляции и плавающему валютному курсу, спустя несколько лет привела к снижению официального уровня инфляции - к концу 2016 г. он сократился до 5,4\% (против 11,4\% в 2014 г., 12,9\% в 2015 г.), а в 2017 г. темп роста потребительских цен составил около 2,5\%, что оказалось даже ниже установленной целевой отметки [4, с. 29-30].

После минимальных значений прироста потребительских цен в первой половине 2018 г. (2,2-2,3\%), во второй половине 2018 г. темп прироста потребительских цен ускорился, но остался в пределах целевого уровня Банка России (4,3\%). В 2019 г. годовая инфляция в России составила $3,0 \%$, что также было в пределах прогнозных оценок Минэкономразвития России $(3,0-3,1 \%)$ и Банка России $(2,9-3,2 \%)$. Ключевыми дезинфляционными факторами в 2019 г. стали снижение внешнего спроса на товары российского экспорта в условиях происходящего замедления мировой экономики, сдерживание инфляции в странах - торговых партнерах России, слабый потребительский спрос [8]. В 2020 г. (по состоянию на октябрь 2020 г.) также не отмечается роста инфляции, превышающего целевые ориентиры макрорегулятора.

Общее давление низкого платежеспособного спроса населения в первые месяцы 2020 г., которое в российских условиях является наиболее значимым фактором снижения темпов инфляции, в марте-апреле 2020 г. было временно приостановлено ростом потребительского спроса в связи с возросшими инфляционными ожиданиями (под влиянием изменений валютного курса). Инфляция росла за счет базовой составляющей, т.е. роста цен на товары и услуги. Однако с мая 2020 г. из-за снижения платежеспособного спроса рост цен в целом снова замедлился. Несмотря на постепенное снятие карантинных ограничений с июня 2020 г. и продолжение экономической жизни в начале осени 2020 г., общий индекс потребительских цен остается почти на 1 п.п. ниже целевого уровня (3,2\% и 4,0\% соответственно) [21, с. 11$]$. 
Несмотря на оптимистичную картину официальных данных, восприятие инфляции населением указывает на более высокие колебания потребительских цен. В частности, согласно данным Банка России и опроса КоронаФОМ, в октябре 2020 г. по сравнению с мартом 2020 г. и октябрем 2019 г. заметно выросли оценки наблюдаемой и ожидаемой инфляции (табл. 4), причем они существенно больше оценок Росстата. Кроме того, группа населения со сбережениями, которая обыкновенно более точно оценивает текущую инфляцию и показывает меньшие инфляционные ожидания, в октябре 2020 г. также дает высокие оценки изменению потребительских цен. Все это свидетельствует о том, что россияне ожидают сохранения высоких темпов роста цен и удорожания часто покупаемых ими товаров и услуг.

Таблиц̧а 4.

Динамика инфляционных ожиданий

\begin{tabular}{|c|c|c|c|c|}
\hline Группа & $\begin{array}{l}\text { Горизонт } \\
\text { ожиданий }\end{array}$ & $\begin{array}{l}2019 \text { г., } \\
\text { октябрь }\end{array}$ & $\begin{array}{c}2020 \text { г., } \\
\text { март }\end{array}$ & $\begin{array}{l}2020 \text { г., } \\
\text { октябрь }\end{array}$ \\
\hline Инфляция, Росстат, \% & декабрь к декабрю & 3,8 & 2,5 & 3,3 \\
\hline \multicolumn{5}{|c|}{ Инфляция, наблюдаемая населением, \% } \\
\hline Медиана (все опрошенные) & \multirow{3}{*}{$\begin{array}{c}\text { предыдущие } \\
12 \text { месяцев }\end{array}$} & 9,4 & 8,3 & 9,6 \\
\hline Подгруппа со сбережениями & & 8,2 & 7,2 & 9,1 \\
\hline Подгруппа без сбережений & & 10,2 & 8,6 & 9,8 \\
\hline \multicolumn{5}{|c|}{ Инфляционные ожидания населения, \% } \\
\hline Медиана (все опрошенные) & \multirow{3}{*}{$\begin{array}{l}\text { следующие } \\
12 \text { месяцев }\end{array}$} & 8,6 & 7,9 & 9,7 \\
\hline Подгруппа со сбережениями & & 7,6 & 6,9 & 9,0 \\
\hline Подгруппа без сбережений & & 9,5 & 8,5 & 10,0 \\
\hline
\end{tabular}

Источник: [16].

Аналогично самооценке материального положения и потребления, восприятие инфляции различается в группах «бедных» и «обеспеченных» россиян. По ощущениям первых за период с октября 2019 г. по октябрь 2020 г. цены росли быстрее, чем раньше (так считают 53\% из них против $36 \%$ среди обеспеченных), тогда как вторые считают, что цены росли так же, как и раньше $(44 \%$ среди обеспеченных против $27 \%$ среди бедных). Инфляционные ожидания выше в группе бедного населения, более трети (37\%) которого уверено, что в следующие 12 месяцев цены будут расти быстрее, 
тогда как среди обеспеченных так считают только 17\%. Наряду с этим, большинство (62\%) представителей наименее обеспеченной группы населения отмечают, что за последние 12 месяцев их «доходы не росли, а цены росли» (среди обеспеченных на это указали $39 \%$ ). Соответственно, адаптация к ценовой нестабильности у данных групп также различается: бедные чаще вынуждены покупать более дешевые товары (35\% против 15\% среди обеспеченных), в принципе покупать реже или вовсе отказываться от некоторых покупок (30\% против 12\%), брать в долг у родственников и знакомых (10\% против 2\%), в то время как обеспеченные для сглаживания изменения цен используют при повседневных расходах ранее накопленные сбережения (12\% по сравнению с 3\% среди бедных).

Наблюдаемые тенденции монетарного неравенства и динамика цен формируют разнообразные риски для материального благополучия населения (табл. 5), предотвращение которых должно быть приоритетом для государственной власти.

Тенденции социально-экономического положения

Таблицุа 5. и возможные риски для населения

\begin{tabular}{|l|l|}
\hline \multicolumn{1}{|c|}{ Тенденции } & \multicolumn{1}{c|}{ Риски } \\
\hline $\begin{array}{l}\text { Стагнация ключевых по- } \\
\text { казателей монетарного } \\
\text { неравенства }\end{array}$ & $\begin{array}{l}\text { - сокрытие бедственного положения групп населе- } \\
\text { ния с доходами ниже ПМ и чуть выше ПМ; } \\
\text { - стагнация и ухудшение условий жизни домохо- } \\
\text { зяйств со средним уровнем дохода }\end{array}$ \\
\hline $\begin{array}{l}\text { Высокая доля расходов на } \\
\text { продовольственные това- } \\
\text { ры, питание }\end{array}$ & $\begin{array}{l}\text { - ограниченные возможности использования } \\
\text { средств в финансовом секторе; } \\
\text { - проблемы с формированием денежного резерва } \\
\text { («на всякий случай», «на пенсию») }\end{array}$ \\
\hline $\begin{array}{l}\text { Низкий горизонт «дожи- } \\
\text { тия» на сбережения }\end{array}$ & $\begin{array}{l}\text { риск повышенной финансовой уязвимости в слу- } \\
\text { чае ограничения или сворачивания экономической } \\
\text { деятельности работодателей }\end{array}$ \\
\hline $\begin{array}{l}\text { Закрепление самоощуще- } \\
\text { ния населения как бедного } \\
\text { и среднеобеспеченного }\end{array}$ & $\begin{array}{l}\text { риск воспроизводства неблагополучия у домохо- } \\
\text { зяйст с низким уровнем дохода и нуждающихся в } \\
\text { постоянной социальной поддержке }\end{array}$ \\
\hline $\begin{array}{l}\text { Закрепление самоощуще- } \\
\text { ния населения как бедного } \\
\text { и среднеобеспеченного }\end{array}$ & $\begin{array}{l}\text { распространение моделей «выживания» и «повсе- } \\
\text { местной экономии», сдерживающих потребитель- } \\
\text { ский спрос }\end{array}$ \\
\hline
\end{tabular}

Источник: составлено авторами. 
Важно понимать, что избыточное доходное неравенство, усугубляющееся неравномерным изменением цен для разных групп населения, негативно влияет на одно из измерений человеческого развития - способность достигать достойного уровня и качества жизни, имея возможность свободного экономического выбора (в плане доступа к обучению, медицинскому обслуживанию, занятости, кредитам, природным ресурсам и проч.). Неравенство подрывает ощущения справедливости и достоинства личности, может приводить к росту протестных настроений, снижению гражданского участия, затруднениям в поддержке правительственных инициатив, что, в свою очередь, может замедлить прогресс в области человеческого и экономического развития. Поэтому органам государственной власти и другим акторам, ответственным за реализацию социальной политики, следует регулярно отслеживать динамику ключевых социально-экономических показателей, анализировать возможные риски для населения и предотвращать их.

\section{Заключение}

В исследовании проанализированы актуальные тенденции в сфере монетарного неравенства и инфляции. Показано, что, несмотря на происходящие с начала 2000-х гг. позитивные трансформации в социально-экономической жизни российского общества, для него по-прежнему характерно избыточное монетарное неравенство: с 2003 г. коэффициент фондов не отпускался ниже 15 раз, индекс Джини - ниже отметки 0,400 , а уровень бедности относительно стабилен с 2008 года. Реальные располагаемые денежные доходы населения, показавшие слабый прирост в 2019 г. после затяжного падения в 2014-2018 гг., во втором квартале 2020 г. вновь сократились (почти на 8\%) из-за влияния сложной эпидемиологической обстановки на экономическую деятельность. Такая динамика находит закономерное отражение в высокой доле расходов на питание в структуре потребительских расходов населения, а также в низких самооценках населением собственного материального положения и потребительских возможностей. 
Сохраняется важность проблемы ценовой нестабильности, которая наиболее негативно сказывается на материальном положении малообеспеченных групп населения. В частности, в 2020 г. заметно выросли оценки наблюдаемой и ожидаемой инфляции, причем они существенно больше оценок Росстата и прогнозов Банка России. Другими словами, население ожидает дальнейшего роста цен и удорожания часто покупаемых им товаров и услуг.

Данные социологических опросов подтверждают вывод об отсутствии значимых улучшений в социально-экономической жизни большинства россиян в последние годы. Большая часть опрошенных россиян не имеет сбережений и кредитов, предпочитает откладывать деньги, а не покупать дорогостоящие товары, а также экономила и отказывалась от запланированных покупок за последний год. Причем проблемное положение бедных слоев населения еще более усугубилось в контексте ограничений экономической и социальной деятельности из-за эпидемиологических ограничений.

Наблюдаемые тенденции в области монетарного неравенства и инфляции несут риски для материального благополучия населения (стагнация и ухудшение условий жизни домохозяйств с низким и средним уровнем дохода, ограниченные возможности использования средств в финансовом секторе, риск повышенной финансовой уязвимости, распространение модели «повсеместной экономии» и проч.). В конечном итоге, длительные негативные воздействия монетарного неравенства и инфляции на главный внутренний ресурс любого государства - население - способны ограничить экономическое развитие страны. Поэтому важно понимать, что в любые периоды экономической жизни страны, включая кризисные, население должно видеть перспективы собственной жизни и развития экономики, иметь свободные средства и уметь грамотно распоряжаться ими. Это сложный процесс, требующий комплексного решения и совместных усилий органов государственной власти, бизнеса и общественности.

Исследование подготовлено в рамках гранта Президента РФ для государственной поддержки молодых российских ученых кандидатов наук № МК-3946.2019.6 


\section{Список литературы}

1. Аганбегян А.Г. Преодоление бедности и сокращение неравенства по доходам и потреблению в России // ЭКО. 2017. № 9. С. 66-84.

2. Александрова О.А., Ярашева А.В. Усиление селективности социальной политики и перспективы снижения бедности // Народонаселение. 2018. № 1. С. 4-22. DOI: 10.26653/1561-7785-2018-21-1-01

3. Анисимова Г.В. Обострение социально-экономического неравенства в России // Общество и экономика. 2020. № 9. С. 125-134. DOI: $10.31857 / \mathrm{S} 020736760011355-9$

4. Белехова Г.В. Потребление versus сбережения: выбор россиян в условиях экономической нестабильности 2015-2017 гг. // ЭКО. 2020. № 6. C. 26-47. DOI: 10.30680/ECO0131-7652-2020-6-26-47

5. Белоусова А.В. Уровень бедности в РФ: пространственный анализ // Вестник Института экономики Российской академии наук. 2020. № 4. C. 73-88. DOI: 10.24411/2073-6487-2020-10043

6. Бобков В.Н., Гулюгина А.А. Неравенство качества и уровня жизни населения регионов // Экономика региона. 2012. № 2 (30). С. 170178. DOI: $10.17059 / 2012-2-15$

7. Бобков В.Н., Одинцова Е.В. Низкие уровень и качество жизни экономически активного населения: критерии идентификации и оценка распространенности // Экономические и социальные перемены: факты, тенденции, прогноз. 2020. Т. 13. № 5. C. 168-181. DOI: 10.15838/esc.2020.5.71.10

8. Бюллетень о текущих тенденциях российской экономики. Динамика доходов населения // Аналитический центр при Правительстве РФ. 2020. Февраль. URL: https://ac.gov.ru/uploads/2-Publications/rus feb_2020.pdf (дата обращения: 07.12.2020).

9. Вызовы цифрового будущего и устойчивое развитие России. Социально-политическое положение и демографическая ситуация в 2017-2018 годах // под ред. Г.В. Осипова, С.В. Рязанцева, В.К. Левашова, Т.К. Ростовской. М.: ИТД «Перспектива», 2018. 716 с.

10. Герсонская И.В. Оценка эффективности деятельности органов государственной власти и управления в России // Наука Красноярья. 2020. T. 9. № 2. C. 49-64. DOI: 10.12731/2070-7568-2020-2-49-64

11. Глазьев С.Ю., Локосов В.В. Оценка предельно критических значений показателей состояния российского общества и их использование в 
управлении социально-экономическим развитием // Экономические и социальные перемены: факты, тенденции, прогноз. 2012. № 4. С. 22-41.

12. Затяжной спад в экономике. Что предпринимают потребители и бизнес // PwC. 2016. URL: https://www.pwc.ru/ru/publications/consumer-businessreport/e-russias-protracted-recession_rus.pdf(дата обращения: 01.12.2020).

13.Зубец А.Н. Социальные предпосылки для прогнозирования потребительской инфляции в России // Инновации и инвестиции. 2019. № 10. С. 175-179.

14. Иванова Н.В., Маркова С.В., Ерина Т.В. Уровень жизни семей с детьми в республике Татарстан: проблемы измерения и повышения // Наука Красноярья. 2020. Т. 9. № 1. С. 55-82. DOI: 10.12731/20707568-2020-1-55-82

15. Ильяшенко В.В., Куклина Л.Н. Взаимосвязь доходов и инфляции с совокупным спросом в российской экономике // Экономика региона. 2018. T. 14. № 4. C. 1477-1487. DOI: 10.17059/2018-4-32

16. Инфляционные ожидания и потребительские настроения // Банк России. 2020. № 10 (46). URL: https://www.cbr.ru/analytics/dkp/ inflationary_expectations/ (дата обращения: 07.12.2020).

17. Картаев Ф.С., Клачкова О.А., Лукьянова А.С. Как инфляция влияет на неравенство доходов в России? // Вопросы экономики. 2020. № 4. C. 54-66. DOI: 10.32609/0042-8736-2020-4-54-66

18. Лапин Н.И., Ильин В.А., Морев М.В. Экстремальные неравенства и социальное государство (Часть 1) // Социологические исследования. 2020. № 1. C. 4-17. DOI: 10.31857/S013216250008378-8

19. Мареева С.В. Монетарное неравенство в России в социологическом измерении // Вестник Института социологии. 2020. Том 11. № 3. С. 78-98. DOI: 10.19181/vis.2020.11.3.664

20. Матыцин М.С., Ершов Э.Б. Исследование дифференциации российского населения по реальным доходам // Экономический журнал ВШЭ. 2012. Т. 16. № 3. С. 318-340.

21. Мониторинг социально-экономического положения и социального самочувствия населения: первое полугодие 2020 // НИУ ВШЭ. URL: https://isp.hse.ru/monitoring

22. Обзор банковского сектора Российской Федерации // Банк России. URL: https://www.cbr.ru/statistics/bank_sector/review/ 
23. Окрепилов В.В. Развитие экономики здоровья для повышения качества жизни // Экономические и социальные перемены: факты, тенденции, прогноз. 2012. № 5. С. 33-47.

24. Основные направления единой государственной денежно-кредитной политики на 2018 год и период 2019 и 2020 годов // КонсультантПлюс. URL: http://www.consultant.ru/document/cons_doc_LAW_282452/12dfaf ad044688f322e56df4e72a12752549a3d1/ (дата обращения: 07.12.2020).

25. Проект коронаФОМ // ФОМ. URL: https:/covid19.fom.ru/

26. Путин В.В. Строительство справедливости. Социальная политика для России // Комсомольская правда. 2012, февраль. URL: https://www. vologda.kp.ru/daily/25833/2807793/ (дата обращения: 11.12.2020).

27. Россияне рекордными с весны темпами сократили свои расходы // РБК. URL: https://www.rbc.ru/society/01/12/2020/5fc5f1ed9a79477f4 b99f4a2 (дата обращения: 01.12.2020).

28. Счет в пользу бедных // Российская газета. 2020. URL: https:// rg.ru/2020/03/16/sociologi-ocenili-raznicu-mezhdu-bogatymi-imaloobespechennymi-rossiianami.html (дата обращения: 01.12.2020).

29. Тихонова Н.Е. Социальная политика в современной России: новые системные вызовы // Общественные науки и современность. 2019. №2. C. 5-18. DOI: 10.31857/S086904990004334-9

30. Человек социальный как цель и источник развития России: научный доклад / колл. авторов под ред. О.А. Александровой и В.В. Локосова. М.: Изд-во «Экон-Информ», 2018. 88 с.

31.Шевяков А.Ю. Мифы и реалии современной социальной политики. М.: ИСЭПН РАН, 2011. 76 с.

32. Шкаратан О.И. Социально-экономическое неравенство в современном мире и становление новых форм социального расслоения в России // Мир России. Т. 27. № 2. С. 6-35. DOI: 10.17323/1811038X-2018-27-2-6-35

33. Ярашева А.В., Макарова Е.А. Типология регионов по потребительскому поведению домохозяйств // Народонаселение. 2015. № 3. 77-84.

34. Blundell R., Dias M.C., Joyce R., Xu X. COVID-19 and Inequalities // Fiscal studies, 2020, vol. 41, no. 2, pp. 291-319. DOI:10.1111/14755890.12232 
35. Bottan N., Hoffmann B., Vera-Cossio D. The unequal impact of the coronavirus pandemic: Evidence from seventeen developing countries // PLoS ONE, 2020, vol. 15, no. 10: e0239797. URL: https://doi.org/10.1371/ journal.pone.0239797

36. Brzezinski M. Income inequality and the Great Recession in Central and Eastern Europe // Economic Systems, 2018, vol. 42, is. 2, pp. 219-247. DOI:10.1016/j.ecosys.2017.07.003

37. Milanovic B. Global inequality: A new approach for the age of globalization. Harvard University Press, 2016. 320 p.

38. Poverty and Shared Prosperity 2016: Taking on Inequality. Washington, DC: World Bank. URL: https://doi.org/10.1596/978-1-4648-0958-3 (accessed: 01.12.2020).

39. Qian Y., Fan W. Who loses income during the COVID-19 outbreak? Evidence from China // Research in Social Stratification and Mobility, 2020, vol. 68. URL: https://doi.org/10.1016/j.rssm.2020.100522

\section{References}

1. Aganbegyan A.G. Preodolenie bednosti i sokrashchenie neravenstva podokhodam i potrebleniyu v Rossii [ Overcoming Poverty and Reducing the Income and Consumption Inequalities in Russia]. EKO [ECO], 2017, no. 9, pp. 66-84.

2. Alexandrova O.A., Yarasheva A.V. Usilenie selektivnosti sotsial'noy politiki i perspektivy snizheniya bednosti [Strengthening the Selectivity of Social policy and poverty reduction prospects]. Narodonaselenie [Population], 2017, no. 1, pp. 4-22. DOI: 10.26653/1561-7785-2018-21-1-01

3. Anisimova G.V. Obostrenie sotsial'no-ekonomicheskogo neravenstva v Rossii [The Aggravation of Socio-Economic Inequality in Russia]. Obshchestvo i ekonomika [Society and Economy], 2020, no. 9, pp. 125-134. DOI: $10.31857 / \mathrm{S} 020736760011355-9$

4. Belekhova G.V. Potreblenie versus sberezheniya: vybor rossiyan v usloviyakh ekonomicheskoy nestabil'nosti 2015-2017 gg. [Consumption vs. Savings: The Choice of Russians in the Conditions of Economic Instability 2015-2017]. EKO [ECO], 2020, no. 6, pp. 26-47. DOI: 10.30680/ ECO0131-7652-2020-6-26-47 
5. Belousova A.V. Uroven' bednosti v RF: prostranstvennyy analiz [Level of Poverty in Russian Federation: a Spatial Analysis]. Vestnik Instituta Ekonomiki Rossiyskoy akademii nauk [The Bulletin of the Institute of Economics of the Russian Academy of Sciences], 2020, no. 4, pp. 73-88. DOI: $10.24411 / 2073-6487-2020-10043$

6. Bobkov V.N., Gulyugina A.A. Neravenstvo kachestva i urovnya zhizni naseleniya regionov [The Inequality of the Quality and Standards of Life of the Population of the Regions]. Ekonomika regiona [Economy of Region], 2012, no. 2, pp. 170-178. DOI: 10.17059/2012-2-15

7. Bobkov V.N., Odintsova E.V. Nizkie uroven' i kachestvo zhizni ekonomicheski aktivnogo naseleniya: kriterii identifikatsii i otsenka rasprostranennosti [Low Level and Quality of Life Among Economically Active Population: Identification Criteria and Assessment of Occurrence]. Ekonomicheskie i sotsial'nye peremeny: fakty, tendentsii, prognoz [Economic and Social Changes: Facts, Trends, Forecast], 2020, vol. 13, no. 5, pp. 168-181. DOI: 10.15838/esc.2020.5.71.10

8. Byulleten' o tekushchikh tendentsiyakh rossiyskoy ekonomiki. Dinamika dokhodov naseleniya [Bulletins on Current Trends in Russian Economy. Household Income Behavior]. Analiticheskiy tsentr pri Pravitel'stve RF [Analytical Center for the Government of the Russian Federation], 2020, February. URL: https://ac.gov.ru/uploads/2-Publications/rus_feb_2020. pdf (accessed: 07.12.2020).

9. Osipov G.V., Ryazantsev S.V., Levashov V.K., Rostovskaya T.K. (eds.). Vyzovy tsifrovogo budushchego i ustoychivoe razvitie Rossii. Sotsial'no-politicheskoe polozhenie i demograficheskaya situatsiya $v 2017$ 2018 godakh [Challenges of the digital future and sustainable development of Russia. Socio-political situation and demographic situation in 2017-2018]. Moscow: Publishing House Perspektiva, 2018, 716 p.

10. Gersonskaya I.V. Otsenka effektivnosti deyatel'nosti organov gosudarstvennoy vlasti i upravleniya v Rossii [Performance Assessment of the Public Authorities and Governance Bodies in Russia]. Nauka Krasnoyar'ya [Krasnoyarsk Science], 2020, vol. 9, no. 2, pp. 49-64. DOI: 10.12731/2070-7568-2020-2-49-64

11. Glazyev S.Y., Lokosov V.V. Otsenka predel'no kriticheskikh znacheniy pokazateley sostoyaniya rossiyskogo obshchestva $\mathrm{i} i \mathrm{kh}$ ispol'zovanie $\mathrm{v}$ 
upravlenii sotsial'no-ekonomicheskim razvitiem [Assessment of the Critical Threshold Values of the Indicators of the State of Russian Society and Their Use in the Socio-Economic Development Management]. Ekonomicheskie i sotsial'nye peremeny: fakty, tendentsii, prognoz [Economic and Social Changes: Facts, Trends, Forecast], 2012, no. 4, pp. 22-41.

12. Zatyazhnoy spad v ekonomike. Chto predprinimayut potrebiteli i biznes [Protracted economic downturn. What consumers and businesses are doing]. URL: https://www.pwc.ru/ru/publications/consumer-business-report/e-russias-protracted-recession_rus.pdf (accessed: 01.12.2020).

13.Zubets A.N. Sotsial'nye predposylki dlya prognozirovaniya potrebitel'skoy inflyatsii v Rossii [Social Prerequisites for Forecasting Consumer Inflation in Russia]. Innovatsii $i$ investitsii [Innovation \& Investment], 2019, no. 10, pp. 175-179.

14. Ivanova N.V., Markova S.V., Erina T.V. Uroven' zhizni semey s det'mi v respublike Tatarstan: problemy izmereniya i povysheniya [The Standard of Living of Families with Children in the Republic of Tatarstan: Problems of Measurement and Improvement]. Nauka Krasnoyar'ya [Krasnoyarsk Science], 2020, vol. 9, no. 1, pp. 55-82. DOI: 10.12731/2070-7568-2020-1-55-82

15. Ilyashenko V.V., Kuklina L.N. Vzaimosvyaz' dokhodov i inflyatsii s sovokupnym sprosom $\mathrm{v}$ rossiyskoy ekonomike [Interrelation of Income, Inflation and Aggregate Demand in the Russian Economy]. Ekonomika regiona [Economy of Region], 2018, vol. 14, no. 4, pp. 1477-1487. DOI: $10.17059 / 2018-4-32$

16. Inflyatsionnye ozhidaniya i potrebitel'skie nastroeniya [Inflation Expectations and Consumer Sentiment]. Bank Rossii [Bank of Russia], 2020, no. 10 (46). URL: https://www.cbr.ru/analytics/dkp/inflationary_expectations/ (accessed: 07.12.2020).

17. Kartaev P.S., Klachkova O.A., Luk'yanova A.S. Kak inflyatsiya vliyaet na neravenstvo dokhodov v Rossii? [How Does Inflation Influence Income Inequality in Russia?]. Voprosy ekonomiki [Voprosy Ekonomiki], 2020, no. (4), pp. 54-66. DOI: 10.32609/0042-8736-2020-4-54-66

18. Lapin N.I., Ilyin V.A., Morev M.V. Ekstremal'nye neravenstva i sotsial'noe gosudarstvo (Chast' 1) [Extremal Inequalities and the Social State (part 1)]. Sotsiologicheskie issledovaniya [Sociological Studies], 2020, no. 1, pp. 4-17. DOI: 10.31857/S013216250008378-8 
19. Mareeva S.V. Monetarnoe neravenstvo v Rossii v sotsiologicheskom izmerenii [Monetary Inequality in Russia in the Sociological Dimension]. Vestnik Instituta sotsiologii [Bulletin of the Institute of Sociology], 2020, vol. 11, no. 3, pp. 78-98. DOI: 10.19181/vis.2020.11.3.664

20. Matytsin M.S., Ershov E.B. Issledovanie differentsiatsii rossiyskogo naseleniya po real'nym dokhodam [The Estimating of Russian Households' Real Income Inequality]. Ekonomicheskiy zhurnal VShE [The HSE Economic Journal], 2012, vol. 16, no. 3, pp. 318-340.

21. Monitoring sotsial'no-ekonomicheskogo polozheniya i sotsial'nogo samochuvstviya naseleniya: pervoe polugodie 2020 [Monitoring of the socio-economic situation and social well-being of the population]. NIU VShE [Higher School of Economics]. URL: https://isp.hse.ru/monitoring

22. Obzor bankovskogo sektora Rossiyskoy Federatsii [Review of the Banking Sector of the Russian Federation]. Bank Rossii [Bank of Russia]. URL: https:/www.cbr.ru/statistics/bank_sector/review/

23. Okrepilov V.V. Razvitie ekonomiki zdorov'ya dlya povysheniya kachestva zhizni [Development of Health Economics for Improving the Quality of Life]. Ekonomicheskie i sotsial'nye peremeny: fakty, tendentsii, prognoz [Economic and Social Changes: Facts, Trends, Forecast], 2012, no. 5 (23), pp. 33-47.

24. Osnovnye napravleniya edinoy gosudarstvennoy denezhno-kreditnoy politiki na 2018 god i period $2019 \mathrm{i} 2020$ godov [The main directions of the state monetary policy for 2018 and for the period of 2019 and 2020] // Konsul 'tantPlyus. URL: http://www.consultant.ru/document/cons_doc_LAW_282452/12dfafad044688f322e56df4e72a12752549a3d1/ (accessed: 07.12.2020).

25. Proekt koronaFOM. URL: https://covid19.fom.ru/

26. Putin V.V. Stroitel'stvo spravedlivosti. Sotsial'naya politika dlya Rossii [Building equity. Social policy for Russia]. Komsomol'skaya pravda, 2012, February. URL: https://www.vologda.kp.ru/daily/25833/2807793/ (accessed: 11.12.2020).

27. Rossiyane rekordnymi s vesny tempami sokratili svoi raskhody [Russians cut their spending at a record pace since spring]. $R B K$. URL: https://www.rbc. $\mathrm{ru} /$ society/01/12/2020/5fc5fled9a79477f4b99f4a2 (accessed: 01.12.2020).

28. Schet v pol'zu bednykh [Counting for the Poor]. Rossiyskaya gazeta. URL: https://rg.ru/2020/03/16/sociologi-ocenili-raznicu-mezhdu-bogatymi-i-maloobespechennymi-rossiianami.html (accessed: 01.12.2020). 
29. Tikhonova N.E. Sotsial'naya politika v sovremennoy Rossii: novye sistemnye vyzovy [Social policy in modern russia: new systemic challenges]. Obshchestvennye nauki i sovremennost' [Social Sciences and Contemporary World], 2019, no. 2, pp. 5-18.

30. Chelovek sotsial'nyy kak tsel' $i$ istochnik razvitiya Rossii [Human Social as the Purpose and Source of Russian Development]; eds. by O.A. Aleksandrova, V.V. Lokosov. Moscow: Ekon-Inform Publ., 2018. 88 p.

31. Shevyakov A.Yu. Mify i realii sovremennoy sotsial'noy politiki [Myths and Realities of Social Policy]. Moscow: ISEPN RAN Publ., 2011. 76 p.

32. Shkaratan O.I. Sotsial'no-ekonomicheskoe neravenstvo v sovremennom mire i stanovlenie novykh form sotsial'nogo rassloeniya $\mathrm{v}$ Rossii [Socio-economic Inequality in the Modern World and the Forming of New Kinds of Social Stratification in Russia]. Mir Rossii, 2018, vol. 27, no 2, pp. 6-35. DOI: 10.17323/1811-038X-2018-27-2-6-35

33. Yarasheva A.V., Makarova E.A. Tipologiya regionov po potrebitel'skomu povedeniyu domokhozyaystv [Typology of Regions by Households' Consumer Behaviour]. Narodonaselenie [Population], 2015, no. 3, pp. 77-84.

34. Blundell R., Dias M.C., Joyce R., Xu X. COVID-19 and Inequalities. Fiscal studies, 2020, vol. 41, no. 2, pp. 291-319. DOI:10.1111/1475-5890.12232

35. Bottan N., Hoffmann B., Vera-Cossio D. The unequal impact of the coronavirus pandemic: Evidence from seventeen developing countries. PLoS ONE, 2020, vol. 15, no. 10: e0239797. URL: https://doi.org/10.1371/ journal.pone.0239797

36. Brzezinski M. Income inequality and the Great Recession in Central and Eastern Europe. Economic Systems, 2018, vol. 42, is. 2, pp. 219-247. DOI:10.1016/j.ecosys.2017.07.003

37. Milanovic B. Global inequality: A new approach for the age of globalization. Harvard University Press, 2016. 320 p.

38. Poverty and Shared Prosperity 2016: Taking on Inequality. Washington, DC: World Bank. URL: https://doi.org/10.1596/978-1-4648-0958-3 (accessed: 01.12.2020).

39. Qian Y., Fan W. Who loses income during the COVID-19 outbreak? Evidence from China. Research in Social Stratification and Mobility, 2020, vol. 68. URL: https://doi.org/10.1016/j.rssm.2020.100522 


\section{ДАННЫЕ ОБ АВТОРАХ}

Россошанский Александр Игоревич, заведующий лабораторией, старший научный сотрудник, кандидат экономических наук Вологодский научный иентр Российской академии наук ул. Горького, 56а, г. Вологда, Вологодская область, 160014, Российская Федерация alexanderrossy@mail.ru

Белехова Галина Вадимовна, научный сотрудник

Вологодский научный иентр Российской академии наук ул. Горького, 56а, г. Вологда, Вологодская область, 160014, Российская Федерация belek-galina@yandex.ru

\section{DATA ABOUT THE AUTHORS}

Rossoshanskii Aleksandr Igorevich, Laboratory Head, Senior Researcher, Candidate of Sciences (Economics)

Vologda Research Center of the Russian Academy of Sciences 56a, Gorky St., Vologda, Vologda region, 160014, Russian Federation

alexanderrossy@mail.ru

SPIN-code: 8099-8434

ORCID: 0000-0002-5975-7863

ResearcherID: I-8184-2016

Belekhova Galina Vadimovna, Researcher

Vologda Research Center of the Russian Academy of Sciences 56a, Gorky St., Vologda, Vologda region, 160014, Russian Federation

belek-galina@yandex.ru

SPIN-code: 7115-1939

ORCID: 0000-0002-6373-9043

ResearcherID: I-8182-2016

Scopus Author ID: 57194492144 